\title{
Rabies in a nine-year-old child: The myth of the bite
}

\author{
Olivier Despond MD ${ }^{1}$, Marisa Tucci MD FRCPC ${ }^{1}$, Hélène Decaluwe MD², \\ Marie-Claude Grégoire MD², Jeanne S Teitelbaum MD FRCPC ${ }^{4}$, \\ Nathalie Turgeon MD FRCPC ${ }^{3}$
}

O Despond, M Tucci, H Decaluwe, M-C Grégoire, JS Teitelbaum, N Turgeon. Rabies in a nine-year-old child: The myth of the bite. Can J Infect Dis 2002;13(2):121-125.

A nine-year-old boy died from rabies encephalitis caused by a rabies virus variant associated with insectivorous bats. The patient was most likely infected in the Laurentian Mountains of western Quebec, but neither the patient nor his parents remembered any direct contact with an animal. The diagnosis was made seven days after the start of symptoms. After examining the most recent cases of rabies in North America, it is obvious that rabies following bat exposure can occur without history of a documented bite. The present case report emphasizes that the general public and medical care providers need better information about the risks associated with exposure to bats.

Key Words: Bat; Children; Encephalitis; Prophylaxis; Rabies

\section{Cas de rage chez un enfant de neuf ans : le mythe de la morsure}

\begin{abstract}
RÉSUMÉ : Un garçon de neuf ans est mort d'une encéphalite rabique causée par une variante du virus de la rage associée aux chauves-souris insectivores. Le patient a été fort probablement infecté dans les Laurentides, dans l'Ouest du Québec, mais ni le patient ni les parents n'avaient souvenir d'un contact direct avec un animal. Le diagnostic a été posé sept jours après l'apparition des symptômes. Après examen des plus récents cas de rage en Amérique du Nord, il apparaît clairement que l'exposition à des chauves-souris peut donner lieu à la maladie, et ce, sans morsure avérée. Le présent exposé de cas montre que la population générale et le personnel médical ont besoin d'être mieux informés sur les risques de rage associés à l'exposition aux chauves-souris.
\end{abstract}

$\mathrm{R}$ abies is a zoonosis responsible for more than 50,000 human deaths every year worldwide, as reported by the World Health Organization. In North America and Europe, human rabies has become a very rare disease, because of the systematic vaccination of domestic animals, massive vaccination campaigns of wild animals, efficacy of rabies postex-

posure prophylaxis (RPEP) and education programs $(1,2)$. While knowledge about the risk of rabies associated with a bite from a terrestrial animal seems relatively adequate among the general public and medical care providers, a lack of information may exist regarding the risk of human rabies following contact with a bat. Between 1980 and 1996,

${ }^{1}$ Pediatric Intensive Care Unit, Department of Pediatrics; ${ }^{2}$ Department of Pediatrics; and ${ }^{3}$ Department of Microbiology and Immunology,

Sainte-Justine Hospital, Université de Montréal, Montréal, Québec; ${ }^{4}$ Department of Medicine, Maisonneuve-Rosemont Hospital, Université de Montréal, Montréal, Québec

Correspondence and reprints: Dr Marisa Tucci, Sainte-Justine Hospital, 3175 Côte Ste-Catherine, Montréal, Québec H3T 1C5.

Telephone 514-345-4931 ext 3261, fax 514-345-4822, e-mail mtucci@justine.umontreal.ca.

Received for publication March 30, 2001. Accepted August 31, 2001 
32 cases of human rabies were diagnosed in the United States, 17 of which occurred after a contact with an indigenous bat (of which only two patients had a definite bite), 14 cases after a dog bite and one after a skunk bite (3). In Canada, three of the four cases of human rabies that have occurred since 1970 followed exposure to bats, the last case dating to 1985 (4). Since September 2000, five cases of human rabies have been reported in the United States (5). One was consecutive to a dog bite contracted in Africa and four have been attributed to bats; in the latter cases, a definite history of a bite was noted in only one case. In 1996, the National Association of State Public Health Veterinarians of the United States stated that "since rabies is endemic in bats, bats should be excluded from houses and surrounding structures to prevent direct association with humans" (6). Possible measures to reduce the bat population to a critical threshold below which the virus might be unable to propagate or to induce immunity in the vector via vaccination seem physically, economically and ecologically impractical (7). The case that we report emphasizes that the bite or the scratch of a rabid bat can go unnoticed and may lead to the development of human rabies.

\section{CASE PRESENTATION}

In late September 2000, a nine-year-old boy with no significant past medical history complained of pain over the upper third of his left arm, associated with a fever of $38.2^{\circ} \mathrm{C}$. His pain was associated with numbness and progressed over the subsequent three days, radiating to the left wrist, left shoulder and lateral aspect of his neck. The pain was worse on palpation, with active movement and at night, causing insomnia. Four days after the onset of symptoms, the patient developed uncontrolled tremors of his left arm, increasing with voluntary movements and stress. The next day, the child presented for medical assessment and was hospitalized.

While his pain remained localized over the left arm, the tremor progressed to the right arm in the next $12 \mathrm{~h}$. He also started complaining of a sore throat and difficulty swallowing cold liquids. The subsequent night was complicated by an intense pruritus over the scalp, neck and torso, with minimal response to diphenhydramine. On day 1 after admission, still conscious and oriented, he exhibited bilateral arm-beating tremors with choreiform and myoclonic movements of the fingers, toes and calves. Deep tendon reflexes were symmetrical, and strength and sensory examinations were normal. At that time, an electroencephalogram revealed a diffuse slowing of cerebral activity with rapid dysrythmia but no epileptic activity. An electromyogram of the left deltoid muscle and computed tomography of the head were normal. Later that day, the patient developed hydrophobia and aerophobia, and he became dysarthric. An evanescent macular rash was noted over the posterior aspect of the neck and back, associated with intense pruritis. He became agitated and experienced transient visual hallucinations. He had significant difficulty drinking but was still able to swallow his saliva.
The following day, the patient developed severe tremor and myoclonus of the face and all extremities, priapism, drooling, pharyngeal spasm, and a feeling of suffocation. He was intubated, heavily sedated and transferred to a tertiary care facility with a presumptive diagnosis of rabies.

Procedures to confirm diagnosis were undertaken, and human rabies immune globulin, rabies vaccine and acyclovir were administered immediately. During the following $24 \mathrm{~h}$, extreme agitation and constant tremors required aggressive analgesia and sedation. On day 3 , high fever, intense keratoconjunctivitis and swollen hyperemic lips were noted; these signs remained present for the next six days. A nonpurpuric maculopapular rash appeared over the face, neck and upper torso, and was confirmed by skin biopsy to be erythema multiforme. A possible right coronary aneurysm was identified by echocardiography, and the patient received intravenous immunoglobulin infusion for a Kawasaki-like syndrome. Over the ensuing two days, his neurological status progressively deteriorated. On day 5 , he developed decerebrate posturing as well as a marked pharyngolaryngeal spasm. The following day, his pupils became dilated and unequal, and he presented transient hemodynamic instability. On day 7 , his pupils became fixed and dilated, priapism disappeared and gasping movements were noted. Sedation was gradually decreased as the patient lost bulbar reflexes and progressed to a profound flaccid coma. Evoked potentials revealed abnormal conduction in the left suprabulbar tract. On day 9, 14 days after the onset of his initial symptoms, the patient presented a clinical picture compatible with brain death, was extubated and died.

A nuchal skin biopsy, cerebrospinal fluid (CSF), saliva and tears were sent to the Animal Disease Research Institute in Nepean, Ontario. The skin biopsy was positive for rabies virus antigen by direct fluorescent antibody test. All samples, except CSF, were positive for rabies virus by reverse-transcriptase polymerase chain reaction (RT-PCR) assay. Molecular analysis of rabies virus isolated from saliva revealed infection by a variant associated with silver-haired and eastern pipistrelle bats. Rabies virus grew from the saliva but not from the other samples. Immunofluorescence testing did not reveal rabies antigen on corneal impression smears, and rabies serology, sent to the Central Public Health Laboratory in Etobicoke, Ontario, was negative. Cerebral magnetic resonance imaging revealed no abnormality. White blood cell count on admission was $6.7 \times 10^{9} / \mathrm{L}$ with a sedimentation rate of $4 \mathrm{~mm} / \mathrm{h}$; CSF white blood cell count was $5 \times 10^{6} / \mathrm{L}$, CSF protein level was $0.56 \mathrm{~g} / \mathrm{L}$ and CSF glucose concentration was $4.5 \mathrm{mmol} / \mathrm{L}$.

The principal findings on autopsy revealed subacute encephalomyelitis with numerous Negri bodies found principally in the hippocampus, thalamus and brain stem; subacute, multifocal inflammation of the dorsal root ganglia of the spinal cord and of the autonomous ganglionic ramifications related to the myocardium, epicardium, esophagus, gut, adrenal gland and retroperitoneum; and subacute myocarditis without coronary aneurysm. 
History revealed no travel outside the province of Quebec. The family had spent five days at a cottage in a wildlife sanctuary in the Laurentian Mountains of western Quebec four weeks before the onset of symptoms of the patient. On the evening of their arrival, while the patient and his younger brother were asleep in their bedroom, the parents noticed a bat flying in the kitchen and removed it promptly. That same night, a bat standing still in the bathroom scared the younger brother. The bat had difficulty flying and was easily grasped by the father and thrown out. Subsequent recollections obtained from the parents after the confirmation of the diagnosis revealed that three days after this event, the patient had showed his mother a small erythematous lesion on his left upper arm with a linear aspect at its centre. No further action was undertaken because the origin of the lesion was unknown at the time.

RPEP was given to the family, 12 close playmates and 44 health care workers with possible percutaneous or mucous exposure to the patient's saliva before confirmation of the diagnosis.

\section{DISCUSSION}

The clinical course of human rabies is classically divided into four stages: incubation period; prodrome; acute neurological phase; and coma. The length of the incubation period presumably depends on the location of the bite, the amount of virus inoculated, and the age and immune status of the patient. The virus is believed to multiply in muscle fibres at the site of the wound, a process that is not painful and does not seem to delay wound healing (8). The virus then seems to bind to nicotinic acetylcholine receptors at the neuromuscular junction, acting like a neurotoxin (9). Before entering into the nerve endings adjacent to the site of viral multiplication, the virus is highly sensitive to the active or passive immune response of the host. If not destroyed at the site of infection, the neurotropic virus migrates centrally via peripheral unmyelinated nerves at a rate estimated between 10 and $400 \mathrm{~mm} /$ day (10). Once in nervous tissue, the virus is protected from the immune system, making immunization inefficient. The incubation period usually lasts between 20 and 90 days, but intervals as short as four days or as long as 19 years have been reported (7).

In the prodromal period, the patient develops the early symptoms of rabies. Pruritus, pain and paresthesia at the site of inoculation or involving the whole limb are classical symptoms that occur in $50 \%$ to $80 \%$ of cases as the virus spreads toward the central nervous system by retrograde axonal transport. Nonspecific symptoms such as fever, chills, fatigue, malaise and insomnia may be present. At this stage, it may remain difficult to diagnose rabies and it is not unusual for patients to be treated with cortisone, antibiotics, acyclovir or quinine. The prodrome usually lasts for two to 10 days.

The acute neurological phase occurs as the virus reaches the brain stem, diencephalon and limbic system, and then moves centrifugally from the central nervous system, infecting those tissues and organs that are most densely innervated.
Two clinical forms of rabies have been described (11). In $80 \%$ of cases, the encephalitic or furious form develops with classical symptoms such as hydrophobia, aerophobia, pharyngeal spasms, hypersalivation and autonomic instability. Periods of visual hallucinations are frequent, but generally awareness remains present. Other clinical signs, such as muscle spasms, rigidity, opisthotonos, anisocoria, seizure and priapism, most of which occurred in our patient, are described in the literature. In $20 \%$ of the cases, a paralytic form of rabies develops, resembling a Guillain-Barré syndrome, which makes the diagnosis of rabies more difficult. In all cases, neurological status progressively deteriorates, aggressive supportive care is necessary to counteract hemodynamic instability and death almost always ensues.

Rabies virus antibody does not appear until late in the clinical course, and viral cultures require much time and rarely allow for early diagnosis; therefore, the most useful diagnostic tests are for viral antigen or nucleic acid. However, intravitam diagnosis is often difficult to make and negative results early in the disease should not rule out the diagnosis of rabies (12). Fluorescent antibody test in a skin biopsy from the nape of the neck just above the hairline, which is a densely innervated area, is considered to be one of the best diagnostic tools for early detection. This assay is easily feasible, has a high sensitivity up to $86 \%$ and requires only a few hours to provide a result. Moreover, this method is very specific (13). Rabies virus antigen can be less reliably detected in corneal impression smears, yielding positive results in only $14 \%$ to $41 \%$ of cases. Furthermore, it can cause significant ocular complications and should be performed by an ophthalmologist $(14,15)$. While RT-PCR assay using saliva has been shown to have reasonable sensitivity $(56 \%$ to $100 \%)$ and can permit rapid identification of the virus in the early phase of the disease, RT-PCR using CSF has a lower sensitivity (22\%) (16). More information about laboratory testing is provided by Elmgren and al (17), found in the present issue of The Canadian Journal of Infectious Diseases.

RPEP has been proved very efficient in preventing the disease. However, the prognosis of patients who develop neurological symptoms is grim. Survival has occurred in only four well-documented cases, where all patients had received some form of prophylaxis, albeit inadequate, before the onset of symptoms (18-21). Therapy with interferon-alpha, ribavirin and intrathecal rabies immune globulin has been attempted, and has not proved efficacious (8,22-24). Our patient was given rabies immune globulin and rabies vaccine on the day that the diagnosis was suspected; an attempt at RPEP was considered worthwhile because the rarity of adverse effects associated with this treatment far outweighed the very poor prognosis associated with the disease.

A few hours after RPEP administration, our patient developed a high fever, a bilateral nonexudative conjunctival hyperemia, swollen and fissured lips, and a polymorphous exanthem; moreover, a right coronary aneurysm was suspected on echocardiography. These clinical signs were 


\section{TABLE 1}

\section{Rabies postexposure prophylaxis}

- Immediate and thorough washing of the wound with soap and water, and if possible, with a povidone-iodine solution.

- Passive immunization with rabies immune globulin $20 \mathrm{U} / \mathrm{kg}$ infiltrated in the area around and into the wound, as soon as possible.

- Active immunization with rabies vaccine injected intramuscularly on day $0,3,7,14$ and 28 , in the deltoid area for adults or the anterolateral thigh for infants and young children, commencing as soon as possible after initial contact or bite

Data from reference 39

considered suggestive of atypical Kawasaki disease (25), and consecutively, nonspecific immune globulins were administered. A biopsy confirmed that the skin lesions were compatible with erythema multiforme, but no coronary aneurysm was found at autopsy. Although no diagnostic certainty was possible in our patient, several potential explanations for the rash were considered. While it was deemed possible that such a reaction could be drug-associated, our patient received neither antibiotics nor anticonvulsants, which might be associated with erythema multiforme and certain clinical features of Kawasaki disease. Furthermore, acyclovir, which our patient did receive, has not been reported to cause such skin lesions $(26,27)$. Secondly, infectious etiologies were considered. Numerous viral infections including herpes simplex and Epstein-Barr virus are known triggers of erythema multiforme $(28,29)$. In addition, adenovirus, enterovirus and measles infections are known causes of Kawasaki-like syndrome (30), and streptococcal and staphylococcal toxin-mediated illness can induce similar skin reactions (31). In our patient, viral and bacterial cultures were positive only for rabies virus, and we could find no case report associating rabies virus with erythema multiforme or Kawasaki-like disease. Finally, it remains possible that these lesions were secondary to a systemic reaction to RPEP.

The most dramatic aspect of this case is the manner in which virus transmission occurred. This patient clearly had no recollection of a bat bite or scratch, and the parents never realized that a significant contact might have happened. Such a lack of suspicion is not uncommon. Among the 24 cases of human rabies transmitted by bats in the United States since 1990, a definite history of a bite was established in only two cases $(8.3 \%)(3,5)$. The virus strains from most patients without a history of a bite were similar to the virus typically isolated from the silver-haired bat and rarely found in other bat species (32). The silver-haired bat is an uncommon species, representing less than $1 \%$ of the bat population, and is found throughout North America. In New York State, $8 \%$ of captured silver-haired bats were shown to be rabid, while less than $1 \%$ of the entire bat population seems to be infected with rabies virus (33). It is hypothesized that the silver-haired bat variant of rabies virus might have unique biological properties that enhance its transmissibility to humans (34). Such a virus might have a higher infectiousness due to a more effective replication in the dermis at lower temperature. Although human contamination through airborne droplets of bat secretions can rarely be a mode of transmission (35), most rabid animals transmit the virus via a break in the skin following a bite or a scratch (36). The teeth from certain bat species are so small and sharp that scrutinizing the wound with an otoscope $(6 \times$ magnification) may be necessary to visualize the pinpoints of a bite (37). This might explain why, in most cases of human rabies related to a contact with a bat, no trace of a bite could be found when patients were examined several days later. Moreover, scratches are a frequent finding in children, particularly during the summer months, and generally do not raise any suspicion.

RPEP prevents the development of rabies efficaciously if given correctly and early after exposure (38). Indeed, if given correctly within five days after exposure, protection against the development of the disease is close to $100 \%$ (39). Although in 1999, the Advisory Committee on Immunization Practice published guidelines for proper administration of RPEP (40), its administration is often inappropriate due to insufficient physician education, misinformation within the general public and poor coordination with public health officials (41). Practically, RPEP begins with immediate and thorough washing of all bite wounds and scratches with soap and water to reduce the viral load at the site of inoculation. Then, RPEP involves the administration of both rabies immune globulin at the site of inoculation and a vaccination schedule that must be respected (Table 1). Some cases of failure associated with immune globulin administration distant from the wound emphasize why rabies immune globulin should be thoroughly infiltrated into the wound and the area surrounding it (42).

Contact with a bat must be considered significant if a bite, a scratch or a mucous membrane exposure has clearly occurred or cannot be reliably excluded, for example, if a bat was found in the room of a sleeping person, a previously unattended child, a mentally disabled person or an intoxicated person (43). If the bat is caught, it should be taken to a veterinarian, euthanized and tested for rabies as soon as possible. Unless the animal can be proven negative for rabies within $48 \mathrm{~h}$ after contact, RPEP should be immediately initiated (44). In most cases, however, the animal is unavailable; it then has to be considered rabid and RPEP should be administered. Despite recent criticism (45), the dramatic circumstances surrounding our patient's history, as well as increasingly frequent reports of human rabies contracted in North America, support the current Canadian guidelines which state that RPEP is appropriate in cases where a significant contact with a bat cannot be excluded (46). The notion that a bite or an overt break in the skin needs to be seen or felt for rabies to be transmitted by a bat is a myth in many cases. 


\section{REFERENCES}

1. Wandeler A, Capt S, Kappeler A, Hauser R. Oral immunization of wildlife against rabies: concept and first field experiment. Rev Infect Dis 1988;10(Suppl 4):S649-53.

2. Dandoy S, Scanlon F. Teaching kids about rabies. Am J Public Health 1999;89:413-4.

3. Noah DL, Drenzek CL, Smith JS, et al. Epidemiology of human rabies in the United States, 1980 to 1996. Ann Intern Med 1998;128:922-30.

4. Varughese P. Human rabies in Canada - 1924-2000. Can Commun Dis Rep 2000;26:210-1.

5. Van Fossan D, Jagoda L, LeSage A, et al. Human rabies - California, Georgia, Minnesota, New York, and Wisconsin 2000. MMWR Morb Mortal Wkly Rep 2000;49:1111-5.

6. National Association of State Public Health Veterinarians, Inc. Compendium of animal rabies control 1996. MMWR Morb Mortal Wkly Rep 1996;45:(RR-3):1-9.

7. Baevsky RH, Bartfield JM. Human rabies: a review. Am J Emerg Med 1993; 11:279-86.

8. Case records of the Massachusetts General Hospital. Weekly clinicopathological exercises. Case 21-1998. N Engl J Med 1998;339:105-12.

9. Jackson AC. Rabies. Can J Neurol Sci 2000;27:278-82.

10. Jackson AC. Case 21-1998: rabies. N Engl J Med 1999;340:65.

11. Hemachudha T, Phuapradit P. Rabies. Curr Opin Neurol 1997;10:260-7.

12. Plotkin SA. Rabies. Clin Infect Dis 2000;30:4-12.

13. Warrell MJ, Looareesuwan S, Manatsathit S, et al. Rapid diagnosis of rabies and post-vaccinal encephalitides. Clin Exp Immunol 1988;71:229-34

14. Schneider LG. The cornea test; a new method for the intra-vitam diagnosis of rabies. Zentralbl Veterinarmed (B) 1969;16:24-31.

15. Zaidman GW, Billingsley A. Corneal impression test for the diagnosis of acute rabies encephalitis. Ophthalmology 1998;105:249-51.

16. Crepin P, Audry L, Rotivel Y, et al. Intravitam diagnosis of human rabies by PCR using saliva and cerebrospinal fluid. J Clin Microbiol 1998;36:1117-21.

17. Elmgren LD, Nadin-Davis SA, Muldoon FT, Wandeler AI. Diagnosis and analysis of a recent case of human rabies in Canada. Can J Infect Dis 2002;13:129-33.

18. Hattwick MAW, Weiss TT, Stechschulte CJ, et al. Recovery from rabies: a case report. Ann Intern Med 1972;76:931-42.

19. Porras C, Barboza JJ, Fuenzalida E, et al. Recovery from rabies in man. Ann Intern Med 1976;85:44-8.

20. Tillotson JR, Axelrod D, Lyman DO. Rabies in a laboratory worker New York. MMWR Morb Mortal Wkly Rep 1977;26:249-50.

21. Alvarez L, Fajardo R, Lopez E, et al. Partial recovery from rabies in a nine-year-old boy. Pediatr Infect Dis J 1994;13:1154-5.

22. Lisic M, Himbele J, Beus I, et al. The clinical picture of rabies in a child. Neurol Croat 1991;40:307-18.

23. Cabrera-Gomez JA, Lopez-Saura P. Recent advances in the treatment of the nervous system disorders with interferon-alpha. Rev Neurol 1999;29:1225-35.

24. Warrell MJ, White NJ, Looareesuwan S, et al. Failure of interferon alfa and tribavirin in rabies encephalitis. BMJ 1989;299:830-3.
25. Newburger JW. Kawasaki disease: who is at risk? J Pediatr 2000;137:149-52.

26. Tatnall FM, Schofield JK, Leigh IM. A double-blind, placebocontrolled trial of continuous acyclovir therapy in recurrent erythema multiforme. Br J Dermatol 1995;132:267-70.

27. Juel-Jensen BE, Khan JA, Pavsol G. High-dose intravenous acyclovir in the treatment of zoster: a double-blind, placebo-controlled trial. J Infect 1983;6(1 Suppl):31-6.

28. Weston WL, Morelli JG. Herpes simplex virus-associated erythema multiforme in prepubertal children. Arch Pediatr Adolesc Med 1997;151:1014-6.

29. Drago F, Romagnoli M, Loi A, Rebora A. Epstein-Barr virus-related persistent erythema multiforme in chronic fatigue syndrome. Arch Dermatol 1992;128:217-22

30. Laupland KB, Dele Davies H. Epidemiology, etiology and management of Kawasaki disease: state of the art. Pediatr Cardiol 1999;20:177-83.

31. Vincent JM, Demers DM, Bass JW. Infectious exanthems and unusual infections. Adolesc Med 2000;11:327-58.

32. Warrel MJ. Human deaths from cryptic bat rabies in the USA. Lancet 1995;346:65-6.

33. Childs JE, Trimarchi CV, Krebs JW. The epidemiology of bat rabies in New York State, 1988-92. Epidemiol Infect 1994;113:501-11.

34. Morimoto K, Patel M, Corisdeo S, et al. Characterization of a unique variant of bat rabies virus responsible for newly emerging human cases in North America. Proc Natl Acad Sci U S A 1996;93:5653-8.

35. Dutta JK, Dutta TK, Das AK. Human rabies: modes of transmissions. J Assoc Physicians India 1992;40:322-4.

36. Ledwith M, Baltimore RS. Management of rabies exposure in pediatric practice. Curr Opin Pediatr 1997;9:478-82.

37. Feder HM, Nelson R, Reiher HW. Bat bite? Lancet 1997;350:1300.

38. Chutivongse S, Wilde H, Supich C, et al. Postexposure prophylaxis for rabies with antiserum and intradermal vaccination. Lancet 1990;335:896-8.

39. Helmick CG. The epidemiology of human rabies postexposure prophylaxis, 1980-1981. JAMA 1983;250:1990-6.

40. Human rabies prevention - United States, 1999: Recommendations of the Advisory Committee on Immunization Practices (ACIP). MMWR Morb Mortal Wkly Rep 1999;48(RR-1):1-21.

41. Moran GJ, Talan DA, Mower W, et al. Appropriateness of rabies postexposure prophylaxis treatment for animal exposure. JAMA 2000;284:1001-7.

42. Wilde H, Stack WF. Case 21-1998: Rabies. N Engl J Med 1999;340:64-5.

43. American Academy of Pediatrics. Rabies. In: Pickering LK, ed. 2000 Red Book: Report of the Committee on Infectious Disease, 25th ed. Elk Grove Village: American Academy of Pediatrics, 2000:475-82.

44. Quebec Immunization Protocol. Quebec: Health and Social Services Ministry, General Direction of the Public Health. Government of Quebec, 1999.

45. Mlot C. Public Health. Bat researchers dispute rabies policy. Science 2000;287:2391-2.

46. National Advisory Committee on Immunization. Canadian Immunizaion Guide, 5th edn. Ottawa: Canadian Medical Association, 1998. 


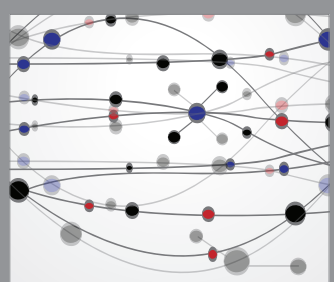

The Scientific World Journal
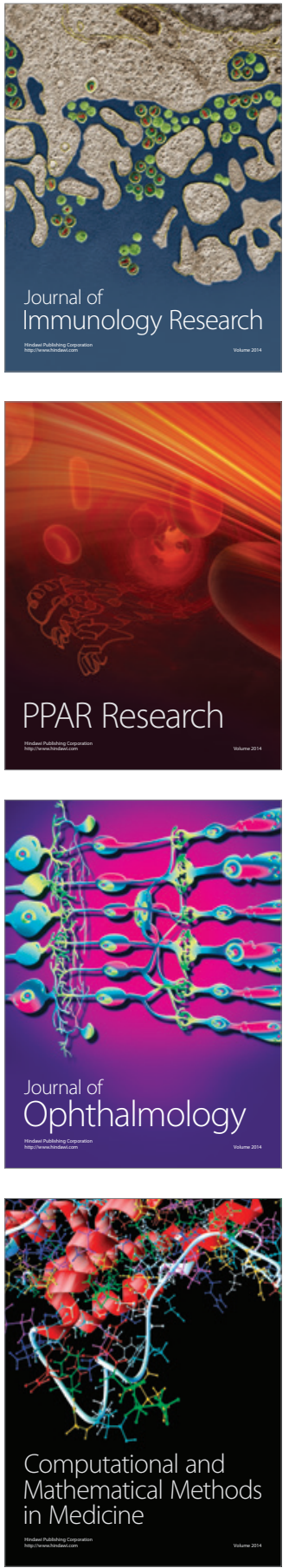

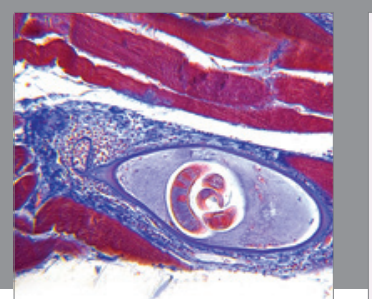

Gastroenterology Research and Practice

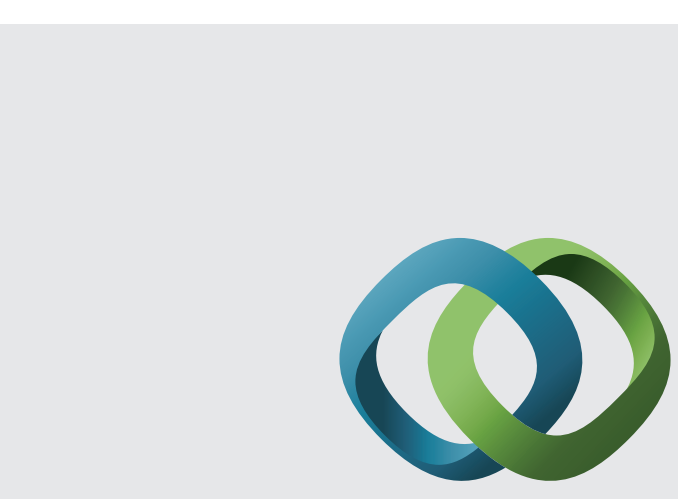

\section{Hindawi}

Submit your manuscripts at

http://www.hindawi.com
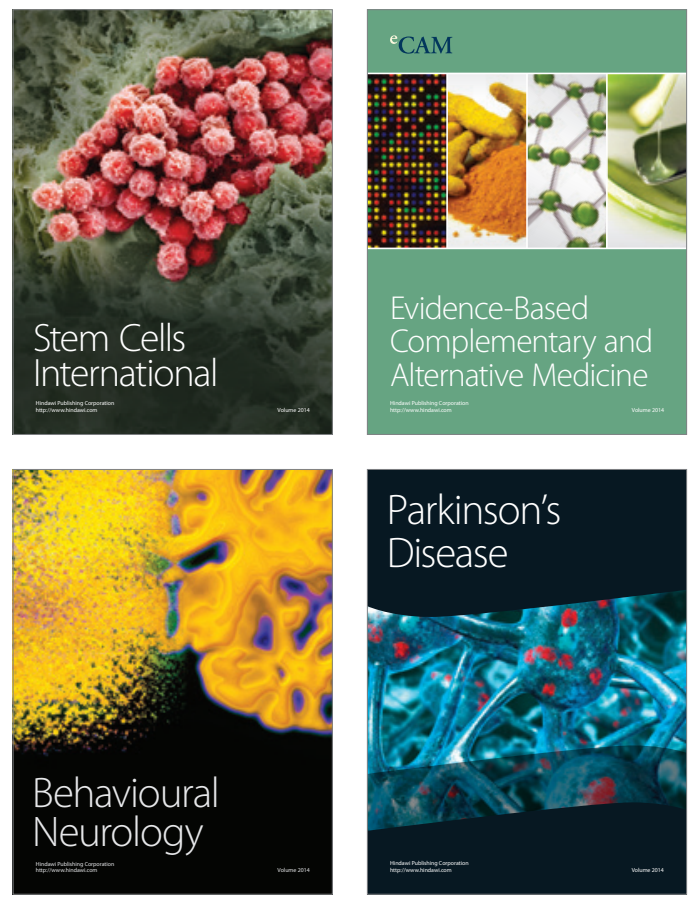
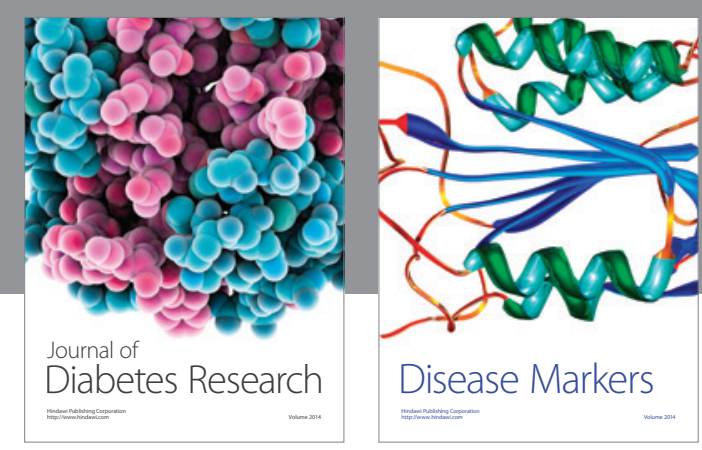

Disease Markers
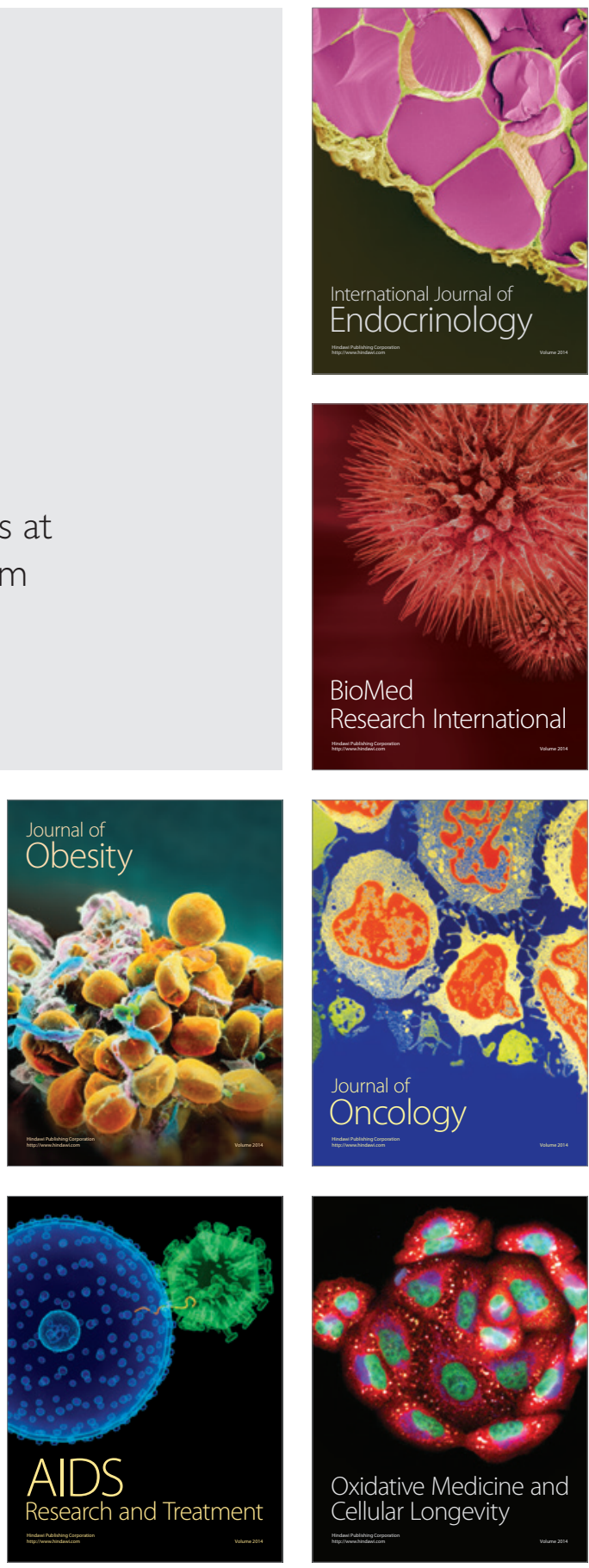